\title{
Mycosis Fungoides and Sézary Syndrome
}

\author{
leva Saulite ${ }^{1}$, Antonio Cozzio ${ }^{1}$, Emmanuella Guenova*
}

\section{ABSTRACT}

Mycosis fungoides (MF) and Sézary syndrome (SS) are two subgroups of cutaneous T-cell lymphomas (CTCL), which belong to the extranodal non-Hodgkin lymphomas. These are rare diseases whose etiology is still not fully understood. Regarding pathogenesis, mycosis fungoides and Sézary syndrome derive from different T-helper cell types and are therefore considered two separate entities according to the current concept.

Mycosis fungoides is clinically characterized by patch, plaque, and tumor stages, although the disease can also manifest as erythroderma. Sézary syndrome is characterized by the presence of erythroderma, defined as redness of the skin covering $>80 \%$ of the total body surface area. In the blood count of patients with mycosis fungoides, a T-lymphocytosis, especially with CD4-positive cells can only be observed in advanced stage IV. One of the typical histological findings is an epidermotropic infiltrate of atypical, CD4-positive T-cells. Characteristic features of Sézary syndrome include atypical T lymphocytes (Sézary cells) in the blood and skin infiltrate. The diagnosis of both mycosis fungoides and Sézary syndrome is based on clinical, histological, and hematological examinations as well as imaging techniques. Staging is based on the tumor-node-metastasisblood (TNMB) classification and is a crucial factor in determining the prognosis. The treatment of mycosis fungoides and Sézary syndrome is carried out according to the stage, whereby local therapies such as UVB phototherapy are used as well as systemic forms of treatment, and in addition, in recent years, targeted therapies have increasingly become part of everyday clinical practice.

Keywords: Cutaneous T-cell lymphoma, extranodal non-Hodgkin's lymphoma, mycosis fungoides, Sézary syndrom

\section{INTRODUCTION}

Mycosis fungoides and Sézary syndrome are rare malignancies that belong to the cutaneous lymphomas and are classified within this group as primary cutaneous T-cell lymphomas. ${ }^{1,2}$ The incidence of cutaneous lymphomas in Europe and the US is estimated to be less than one new case per 100,000 population. ${ }^{3}$ Mycosis fungoides is considered the most common entity in this group, accounting for about $50 \%$ of all cutaneous lymphomas, whereas Sézary syndrome is a rare form, accounting for only approximately 2 to $3 \%{ }^{3,4}$ Mycosis fungoides most commonly occurs between the ages of 40 and 70 and affects more men than women., ${ }^{5,6}$ The incidence of mycosis fungoides and its variants is estimated to be between 1:350,000 and 1:110,000 cases, and the mycosis fungoides accounts for 80 to $90 \%$ of these cases. ${ }^{6}$ Sézary syndrome occurs most often in the 5 th decade of life and also affects more males than females, and more African Americans than Caucasians. ${ }^{7,8}$ The annual incidence of Sézary syndrome is less than $1: 1,000,000$ cases. $^{7,9}$

\section{CLASSIFICATION}

The World Health Organization (WHO) European Organization for Research and Treatment of Cancer (EORTC) classification of cutaneous lymphomas is based on clinicopathological as well as immunohistological and molecular biology criteria. ${ }^{1,2}$ It therefore also provides a rough estimation of the prognosis of the respective subtype. ${ }^{5}$ The current version of the WHO-EORTC classification, published in 2018, is shown in Table 1 with an overview of the cutaneous T-cell lymphoma subtypes, including mycosis fungoides and Sézary syndrome. ${ }^{10}$
${ }^{1}$ Department of Dermatology and Venereology and Allergology, Kantonsspital St. Gallen, St. Gallen, Switzerland

${ }^{2}$ Department of Dermatology, Lausanne University Hospital (CHUV) and Faculty of Biology and Medicine, University of Lausanne, Lausanne, Switzerland

*Corresponding Author: Prof. Dr Emmanuella Guenova Department of Dermatology, Lausanne University Hospital (CHUV) Rue du Bugnon 21, Lausanne, CH-1011, Switzerland emmanuella.guenova@unil.ch

DOI: $10.36000 / \mathrm{hbT} . \mathrm{OH} .2021 .08 .036$ ISSN: 2673-2092 (Print) and 26732106 (Online)

This article was received on April 20, 2021

This article was accepted on May 31, 2021

This article was published on June 11, 2021

Saulite I et al. Mycosis fungoides and Sézary Syndrome. healthbook TIMES Onco Hema 2021; (8): 22-31 
Table 1. WHO-EORTC classification of cutaneous T-cell lymphomas (update 2018). EBV, Epstein-Barr virus; NDA, no data available; NK, natural killer cells; NOS, not otherwise specified (according to ${ }^{10}$ ).

\begin{tabular}{|c|c|c|}
\hline & Frequency $(\%)$ & Disease-specific 5-year survival rate (\%) \\
\hline Mycosis fungoides & 39 & 88 \\
\hline Mycosis fungoides variants & & \\
\hline - Folliculotropic MF & 5 & 75 \\
\hline - Pagetoid reticulosis & $<1$ & 100 \\
\hline - Granulomatous slack skin & $<1$ & 100 \\
\hline Sézary syndrome & 2 & 36 \\
\hline Adult T-cell leukemia/lymphoma & $<1$ & NDA \\
\hline Primary cutaneous CD30-LPDs & & \\
\hline - Primary cutaneous anaplastic large-cell lymphoma (C-ALCL) & 8 & 95 \\
\hline - Lymphomatoid papulosis & 12 & 99 \\
\hline Subcutaneous panniculitis-type T-cell lymphoma & 1 & 87 \\
\hline Extranodal NK/T-cell lymphoma, nasal type & $<1$ & 16 \\
\hline Chronic active EBV infection & $<1$ & NDA \\
\hline Primary cutaneous peripheral T-cell lymphomas, rare subtypes & & \\
\hline 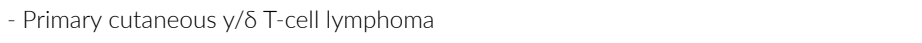 & $<1$ & 11 \\
\hline $\begin{array}{l}\text { - Primary cutaneous CD8-positive aggressive epidermotropic cytotoxic T-cell lymphoma } \\
\text { (preliminary) }\end{array}$ & $<1$ & 31 \\
\hline $\begin{array}{l}\text { - Primary cutaneous CD4-positive small/medium T-cell lymphoproliferative disorder } \\
\text { (preliminary) }\end{array}$ & 6 & 100 \\
\hline - Primary cutaneous acral CD8-positive T-cell lymphoma (preliminary) & $<1$ & 100 \\
\hline Primary cutaneous peripheral T-cell lymphomas, NOS & 2 & 15 \\
\hline
\end{tabular}

\section{ETIOLOGY/PATHOGENESIS}

The etiology of both mycosis fungoides and Sézary syndrome remains poorly understood. ${ }^{6,7}$ Viruses, such as human T-cell leukemia virus type 1 , have been previously suggested as drivers of the disease ${ }^{11}$, but recent studies do not present enough evidence to support the viral hypothesis in the pathogenesis of MF and SS..$^{12}$ Antigen-driven T-cell lymphoproliferation or dyscrasia following medication use ${ }^{13}$, as well as genetic factors, i.e., human leukocyte antigen (HLA) class II alleles predisposing to the disease ${ }^{14,15}$ have been reported. Recent attempts to profile the genomic landscape of CTCL have demonstrated its high heterogeneity. Although the pathogenesis of the disease cannot be attributed to a small subset of well-defined somatic mutations, copy number variations, fusion proteins, and somatic mutations in diverse cellular and signaling pathways might contribute to the pathogenesis of the disease. ${ }^{15-18}$ Those include alterations in factors functioning in epigenetic regulation, DNA damage response, cell cycle control, programmed cell death, and T-cell receptor (TCR) signaling, as well as nuclear factor $(\mathrm{NF})-\mathrm{kB}$ and Janus kinase (Jak)/signal transducer and activator of transcription (STAT) pathways..$^{17-21}$ Next to those intrinsic drivers, also extrinsic drivers, most commonly Staphylococcus aureus (SA) and its toxins, are under debate. ${ }^{22}$ However, epidemiological studies could so far not reliably identify environmental exposure as a trigger for the disease. ${ }^{23}$

Mycosis fungoides tumor cells arise from so-called "skinresident effector memory $\mathrm{T}$ cells.". ${ }^{\text {. }}$ These cells are located in the peripheral tissues, e.g., in the skin, where they mediate the local immune response independently of the rest of the immune system in the blood and lymph nodes directly on-site as part of the local immune defense. ${ }^{24,25}$ These cells also survive for a very long time and appear to maintain a stable adhesion to their target tissue. This also explains why the circumscribed skin lesions characteristic of mycosis fungoides often remain restricted to the skin for many years. ${ }^{24,25}$ In contrast, the malignant cells of Sézary syndrome arise from so-called "central memory T cells", which typically circulate between peripheral organs, blood and the lymphatic system and thereby play an important role in communication between these compartments. ${ }^{24,25}$ Accordingly, the tumor cells of Sézary's syndrome infiltrate the skin diffusely and can also rapidly migrate into the blood and lymph nodes. ${ }^{24,25}$ Hence, 
the current understanding is that mycosis fungoides and Sézary syndrome are two distinct entities within cutaneous $\mathrm{T}$-cell lymphomas, differing not only in prognosis but also in pathogenesis. ${ }^{26}$

\section{CLINICAL PROFILE}

\section{MYCOSIS FUNGOIDES}

Different clinical stages are distinguished in mycosis fungoides, although not all patients go through each stage. Mycosis fungoides initially manifests as well-circumscribed, erythematous, macular lesions. Sometimes these lesions may appear slightly brownish (initial or patch stage), which can remain unchanged for years or decades (Figure 1A). ${ }^{5,26}$ Since these lesions can mimic other inflammatory dermatoses, the diagnosis of mycosis fungoides is delayed by a median period of up to 36 months after the onset of the initial symptoms. ${ }^{27}$ The subsequent progression of the disease may vary and manifest as sharply circumscribed, squamous lesions with mild scaling (plaque stage, Figure 1B), tumors (tumor stage, Figure 1C), or erythroderma (Figure 1D)., ${ }^{5,26}$ It is important to distinguish between the latter and Sézary syndrome since the treatment and prognosis of these two conditions differ. ${ }^{5,26}$ Folliculotropic mycosis fungoides, pagetoid reticulosis, and granulomatous slack skin are distinct subtypes of mycosis fungoides that are differentiated by their clinical and histopathological characteristics, clinical progression, and prognosis. While the latter two entities are very rare, folliculotropic mycosis accounts for about $5-15 \%$ of all mycosis fungoides. Clinically, this subtype has the characteristic grouped follicular papules, preferably in the head and neck region, as well as acneiform lesions and associated alopecia. ${ }^{5}$

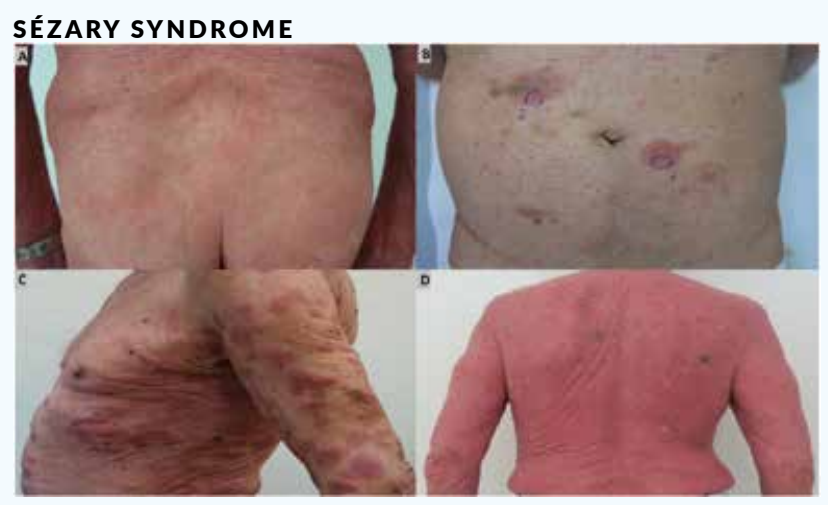

Figure 1. Manifestations of mycosis fungoides: patch stage (A), plaque stage (B), tumor stage (C), erythrodermic mycosis fungoides (D) (according to ${ }^{26}$.
Sézary Syndrome is clinically characterized by an erythroderma affecting more than $80 \%$ of the body surface. ${ }^{28}$ Only approximately $25 \%$ of patients initially present with the erythroderma, but over $86 \%$ develop the characteristic erythroderma during the disease. ${ }^{28}$ Consequently, patients often present clinically non-specific at the beginning, which leads to a delayed diagnosis of the disease by a mean period of 4.2 years. ${ }^{28}$ Other symptoms of Sézary syndrome include alopecia, onychodystrophy, palmoplantar hyperkeratosis, and intensive pruritus, which is associated with significant distress for the patient..$^{28}$ The reduction of cutaneous integrity leads to an increased risk of infection by the resident cutaneous flora, e.g., Staphylococcus aureus. ${ }^{29-31}$ Tumorous skin infiltrates associated with edema as well as hypoalbuminemia may lead to fluid loss. The obligatory findings are generalized enlarged lymph nodes, whereas in the early stages of the disease, often non-specific lymphadenopathy can be detected, in the majority of cases, a specific involvement can be confirmed at a later stage. ${ }^{32}$

\section{LABORATORY/HISTOLOGY}

\section{MYCOSIS FUNGOIDES}

In the blood count of patients with mycosis fungoides a significant T-lymphocytosis (mainly $\mathrm{CD}^{+}$cells) with increased immaturity of lymphocytes, eosinophilia, and atypical T-lymphocytes (Sézary or Lutzner cells) can only be detected in advanced stage IV. ${ }^{6}$ Occasionally, elevated IgE levels may also be observed. ${ }^{6}$

Histological examination at the patch stage of the disease shows a variably dense, band-like or lichenoid, subepidermal infiltrate of small, epidermotropic, neoplastic CD4-positive lymphocytes, a mixture of non-neoplastic CD4- and CD8positive lymphocytes and dendritic cells, however, only scant atypical cells can be found. ${ }^{33,34} \mathrm{~A}$ typical feature is the lining-up phenomenon, a pearl string-like accumulation of lymphocytes at the dermo-epidermal junction zone. ${ }^{33,34}$ Moderate epidermotropism, i.e., migration of atypical lymphoid and monocytoid cells into the epidermis, can be demonstrated. . $^{33,34}$ The migrated cells often appear enlarged in the epidermis and are surrounded by an optically empty halo (halo cells). ${ }^{33,34} \mathrm{~A}$ typical spongiosis is absent, as is a pronounced parakeratosis, i.e., a distinction from eczema. ${ }^{33,34}$ Pautrier's microabscesses intraepidermal accumulations of numerous lymphocytes are detectable but occur rather rarely at this stage. ${ }^{35}$ 
In the plaque stage, histological examination reveals a dense, band-like infiltrate in the upper dermis consisting of atypical, small, or medium-sized lymphocytic cells. ${ }^{33,34,36}$ Eosinophils and histiocytes may be present in varying densities. ${ }^{33,34}$ Pronounced epidermotropism with Pautrier microabscesses is characteristic of this phase. ${ }^{33-35}$ The epidermis is frequently acanthotic with parakeratotic keratinization. Adnexotropism, a special form of epitheliotropism, is frequently observed, in which the hair follicles and sweat glands are particularly affected by the influx of infiltrating cells. ${ }^{33-35}$

Histopathological examination during the tumor stage reveals a dense, diffuse, or nodular dermal infiltrate of atypical, medium-sized lymphocytic cells, often involving the subcutaneous fat tissue. ${ }^{37,38}$ Eosinophils and histiocytes are present to varying degrees. ${ }^{37,38} \mathrm{~A}$ high level of mitotic activity may also be observed. ${ }^{6}$ In approximately $25 \%$ of the cases of mycosis fungoides in the tumor stage transform into diffuse, large-cell lymphoma, which may be either CD30-negative or CD30-positive. ${ }^{39}$ This significantly impairs the prognosis of the affected patients..$^{39,40}$

\section{SÉZARY SYNDROME}

In addition to the clinical findings of pruritic erythroderma and generalized lymphadenopathy, Sézary syndrome is characterized by neoplastic T-cells with cerebriform nuclei and cytoplasmic glycogen granules (Sézary or Lutzner cells) in the blood, skin, and lymph nodes. Based on the consensus recommendations of the International Society of Cutaneous Lymphomas and the WHO-EORTC classification, Sézary syndrome can be defined by erythroderma as an obligatory symptom, plus at least two of the following criteria: ${ }^{8,10,41,42}$

- A Sézary cell count of $>1000 / \mu l$ in the peripheral blood

- Immunophenotypic T-cell abnormalities with an elevated CD4/CD 8 ratio $\geq 10$, or an increase of $\geq 30 \%$ in $\mathrm{CD}^{+}$and $\mathrm{CD}^{-}$cells, or an increase of $\geq 40 \%$ in $\mathrm{CD}^{+}{ }^{+}$and $\mathrm{CD} 26^{-}$cells

- The presence of a monoclonal T-cell receptor (TCR) population in the blood

\section{Current EORTC proposal: $:^{43}$}

- $\mathrm{B} 0<250 / \mu \mathrm{L}$

- $\mathrm{B} 1 \geq 250 / \mu \mathrm{L}$ and $<1000 / \mu$

- $\mathrm{B} 2 \geq 1000 / \mu \mathrm{L} \mathrm{CD} 4^{+} \mathrm{CD} 7^{-}$or $\mathrm{CD}^{+} \mathrm{CD} 26$ cells per

- $\mu \mathrm{L}$ blood
Histological examination of Sézary syndrome is often nonspecific. Only in about $50 \%$ of cases, the diagnosis of SS can be made histologically. The histopathological features of skin biopsies in Sézary syndrome and in mycosis fungoid skin disease are very similar and thus can hardly be distinguished from each other. ${ }^{44}$

Histology reveals a significantly increased degree of epidermotropism and more intraepidermal atypical lymphocytes in SS biopsies compared with erythrodermic inflammatory dermatosis (EID). SS show significantly more dermal cerebriform and blastic lymphocytes than EID. Immunohistochemistry reveals a significant loss of CD7 expression in SS case. The lymphocytic infiltrate in SS skin samples express PD-1, MUM-1 and Ki-67. A multivariate analysis identified CD7 loss, increased numbers of small cerebriform lymphocytes, low numbers of CD8(+) lymphocytes and increased proliferation (Ki-67(+) lymphocytes) as the strongest indicators for the diagnosis of SS..$^{44,45}$

DIAGNOSIS, STAGING AND PROGNOSIS

DIAGNOSTIC APPROACH TO MYCOSIS FUNGOIDES AND SÉZARY SYNDROME

Diagnosis, staging, and also the subsequent therapy planned for mycosis fungoides and Sézary syndrome are based on a detailed medical history, precisely documented skin examination, histological examinations (including immunophenotyping and clonality detection if required), laboratory analyses (including flow cytometry or respectively fluorescence-activated cell sorting (FACS)). These measures are supplemented by the imaging procedures, such as lymph node ultrasound and whole-body $\mathrm{CT} .^{26}$ The molecular biology and histological findings should not be overestimated compared to the clinical presentation and anamnesis, otherwise there is a risk of overtreatment. ${ }^{26}$ For example, monoclonality observed during biomolecular testing is also frequently associated with inflammatory disease, the detection of which is therefore often only of limited diagnostic and prognostic relevance. ${ }^{26}$ The specific recommendations of the Working Group on Dermatological Oncology (Arbeitsgemeinschaft Dermatologische Onkologie - $A D O$ ), the German Cancer Society, and the German Dermatological Association are presented in the current S2-k Guideline "Cutaneous Lymphomas" covering the diagnostics and staging of mycosis fungoides and Sézary syndrome, depicted in Table 2. 
Table 2. Diagnostics and staging of mycosis fungoides and Sézary syndrome (according to ${ }^{1}$ ). ${ }^{*}$ The recommendations applying to primary staging. Individually adapted staging examinations should be performed during annual staging examinations, based on the treatment and progress and in case of aggressive lymphoma types. **Whole-body CT: CT of neck, thorax, abdomen, pelvis with intravenous administration of contrast agent. ${ }^{* * *}$ Retrospective examinations with low case numbers revealed for the most part a clear superiority of 18F-FDG PET/CT over standard imaging methods, particularly for the detection of lymph node and organ manifestations. At the present time, however, larger prospective studies providing sufficient evidence are still lacking. As a rule, the costs of PET-CT examinations for this indication are not covered by statutory medical insurers in Germany. FACS, fluorescence-activated cell sorting - flow cytometry; PCR, polymerase chain reaction; PET-CT, positron emission tomography - computed tomography; 18F-FDG, 18 F-fluorodeoxyglucose.

\begin{tabular}{|c|c|c|c|}
\hline & \multicolumn{2}{|c|}{ Examination } & Method/procedure \\
\hline History & \multicolumn{2}{|c|}{ - Cutaneous manifestations - type, extent and development over time } & \\
\hline Clinical examination & \multicolumn{2}{|c|}{$\begin{array}{l}\text { - Thorough inspection of the skin } \\
\text { - Lymph node status } \\
\text { - Palpation of liver and spleen } \\
\text { - B symptoms }\end{array}$} & $\begin{array}{l}\text { - Recommendation: use physical exam form and photographic } \\
\text { documentation }\end{array}$ \\
\hline Laboratory analyses & \multicolumn{2}{|c|}{$\begin{array}{l}\text { - Differential blood count, electrolytes, liver enzymes, creatinine, } \\
\text { lactate dehydrogenase, C-reactive protein } \\
\text { - Immunoelectrophoresis if applicable* } \\
\text { - Borrelia serology if applicable* } \\
\text { - Special hematological examinations if applicable* } \\
\text { - Further laboratory analyses depending on the treatment plan }\end{array}$} & $\begin{array}{l}\text { In case of erythrodermic T-cell lymphomas: } \\
\text { - Blood smear for Sézary cells } \\
\text { - FACS, CD4/CD8 ratio, determination of CD4+/CD7- cells and/or } \\
\text { CD4 } 4^{+} / C D 26 \text { cells } \\
\left.\text { - Clonality analysis of blood (PCR, BIOMED-2 Protocol }\left({ }^{47}\right)\right) \\
\text { - Bone marrow biopsies are not indicated for diagnosis }\end{array}$ \\
\hline Biopsy & \multicolumn{2}{|c|}{$\begin{array}{l}\text { - Histology, immunohistochemistry, and molecular biological tests } \\
\text { (determination of clonality acc. to BIOMED-2 Protocol as needed) of } \\
\text { lesional skin, suspiciously enlarged lymph nodes and as indicated in } \\
\text { case of suspected organ infiltration }\end{array}$} & $\begin{array}{l}\text { In cases of T-cell lymphomas: } \\
\text { - PCR analyses of the T-cell receptor chain (TCR-gamma-PCR, } \\
\text { BIOMED-2 Protocol) }\end{array}$ \\
\hline \multicolumn{4}{|c|}{ Staging examinations } \\
\hline \multicolumn{2}{|l|}{ Clinical profile } & \multicolumn{2}{|c|}{ Instrument-based investigations } \\
\hline \multicolumn{2}{|l|}{ Mycosis fungoides } & \multicolumn{2}{|c|}{$\begin{array}{l}\text { - Chest X-ray } \\
\text { - Abdominal and lymph node ultrasound }\end{array}$} \\
\hline \multicolumn{2}{|c|}{$\begin{array}{l}\text { Mycosis fungoides variants: } \\
\text { - Folliculotropic mycosis fungoides } \\
\text { - Pagetoid reticulosis } \\
\text { - Granulomatous slack skin }\end{array}$} & \multicolumn{2}{|c|}{$\begin{array}{l}\text { - Chest X-ray } \\
\text { - Abdominal and lymph node ultrasound }\end{array}$} \\
\hline \multicolumn{2}{|c|}{ Mycosis fungoides starting from stage IIB } & \multicolumn{2}{|c|}{$\begin{array}{l}\text { - Whole-body } \mathrm{CT}^{* *} \\
\text { - Lymph node ultrasound } \\
\text { - PET-CT if applicable*** }\end{array}$} \\
\hline \multicolumn{2}{|l|}{ Sézary syndrome } & \multicolumn{2}{|c|}{$\begin{array}{l}\text { - Whole-body } \mathrm{CT}^{* *} \\
\text { - Lymph node ultrasound } \\
\text { - PET-CT if applicable }\end{array}$} \\
\hline
\end{tabular}

\section{DIFFERENTIAL DIAGNOSES OF MYCOSIS FUNGOIDES AND SÉZARY SYNDROME}

From a differential diagnostic point of view, Sézary syndrome and mycosis fungoides, are difficult to distinguish from each other since these two conditions share many clinical similarities. ${ }^{8}$ Examination of peripheral blood involvement is helpful in this regard: findings are absent or minimal in mycosis fungoides, but are an essential component of Sézary syndrome (Sézary cell count in the peripheral blood $>1000 / \mu l) .{ }^{8}$ It is also important to differentiate the initial stage of this disease from parapsoriasis en plaques, microbial or atopic eczemas, psoriasis vulgaris and pityriasis rosea. ${ }^{6}$ During the plaque stage, mycosis fungoides must be differentiated from cutaneous pseudolymphomas, and leukemias, lupus erythematodes tumidus, urticaria pigmentosa, and tinea corporis. ${ }^{6}$ During the tumor stage of the disease, other cutaneous T-cell lymphomas, and cutaneous B-cell lymphomas must also be excluded. ${ }^{6}$ Other, non-neoplastic differential diagnoses of Sézary 
Table 3. TNMB classification of mycosis fungoides and Sézary syndrome according to the revised ISCL/EORTC and resulting staging incl. prognoses in the form of disease-specific 5-year survival rate (according to ${ }^{1,8,46,48,49}$ ).

\begin{tabular}{|c|c|c|c|c|c|c|c|}
\hline TNMB stage & Description & Stage & $T$ & $\mathrm{~N}$ & $M$ & B & Prognosis: 5-year survival \\
\hline \multicolumn{2}{|l|}{ Skin (T) } & & & & & & rate (\%) \\
\hline \multirow[t]{2}{*}{$\mathrm{T} 1$} & \multirow{2}{*}{$\begin{array}{l}\text { Macules, papules and/or plaques } \leq 10 \% \text { of } \\
\text { Body surface area (BSA) }\end{array}$} & IA & 1 & 0 & 0 & 0 or 1 & 98 \\
\hline & & $\mathrm{IB}$ & 2 & 0 & 0 & 0 or 1 & 89 \\
\hline T1a & Patches only & $\| \mathrm{A}$ & 1 or 2 & 1 or 2 & 0 & 0 or 1 & 89 \\
\hline T1b & Plaques \pm patches & $\| \mathrm{B}$ & 3 & $0-2$ & 0 & 0 or 1 & 56 \\
\hline \multirow[t]{2}{*}{ T2 } & \multirow{2}{*}{$\begin{array}{l}\text { Patches, papules or plaques ( } \geq 10 \% \text { of skin } \\
\text { surface) }\end{array}$} & IIIA & 4 & $0-2$ & 0 & 0 & 54 \\
\hline & & $\| \mathrm{B}$ & 4 & $0-2$ & 0 & 1 & 48 \\
\hline T2a & Patches only & $\mathrm{IVA}_{1}$ & $1-4$ & $0-2$ & 0 & 2 & 41 \\
\hline $\mathrm{T} 2 \mathrm{~b}$ & Plaques \pm patches & $\mathrm{IVA}_{2}$ & $1-4$ & 3 & 0 & 0 or 2 & 23 \\
\hline T3 & $\geq 1$ tumor ( $\geq 1 \mathrm{~cm}$ in diameter) & IVB & $1-4$ & $0-3$ & 1 & 0 or 2 & 18 \\
\hline
\end{tabular}

\begin{tabular}{|l|l|}
\hline T4 & Generalized erythroderma ( $\geq 80 \%$ of BSA) \\
\hline Lymph nodes (N) & \\
\hline
\end{tabular}

\begin{tabular}{|c|c|c|}
\hline & \multirow{4}{*}{$\begin{array}{l}\text { syndrome include erythrodermic psoriasis, atopic dermatitis } \\
\text { or other forms of dermatitis, pityriasis rubra pilaris, adverse } \\
\text { drug reactions and idiopathic erythroderma. }{ }^{8} \text { Distinguishing } \\
\text { between early-stage Sézary syndrome, and erythrodermic } \\
\text { inflammatory dermatoses can be challenging. }{ }^{8}\end{array}$} \\
\hline NO & No palpable peripheral lymph nodes & \\
\hline N1 & $\begin{array}{l}\text { Palpable lymph nodes; no histological evidence } \\
\text { of } \mathrm{CTCL}\left(\mathrm{NCILN} \mathrm{N}_{0-2}\right)\end{array}$ & \\
\hline $\mathrm{N} 1 \mathrm{a}$ & Clone-negative & \\
\hline
\end{tabular}

\section{TUMOR STAGING AND PROGNOSIS}

Tumor staging of mycosis fungoides and Sézary syndrome is based on the revised, internationally recognized TNM classification of the International Society for Cutaneous Lymphomas (ISCL) and the European Organization for Research and Treatment of Cancer (EORTC). ${ }^{46}$ This classification system includes skin involvement, primary tumor $(\mathrm{T})$, lymph node involvement $(\mathrm{N})$, and distant metastases (M), as well as detection of atypical lymphocytes or Sézary cells in the peripheral blood (B) and is therefore referred as TNMB classification. ${ }^{46}$ This classification defines the different stages of the disease, and these stages are associated with a certain prognosis, mean 5-year survival rates respectively (Table 3). ${ }^{46,48}$

In addition to the stage of the disease, other factors also impact the prognosis in patients with mycosis fungoides or Sézary syndrome. A univariate analysis revealed that advanced age, male sex, elevated lactate dehydrogenase (LDH) levels and large cell transformation had a negative impact on survival and increased the risk of disease progression, respectively. ${ }^{49}$ On the other hand, patients with hypopigmented, poikilodermatous mycosis fungoides or 
mycosis fungoides with lymphomatoid papulosis have a better chance of survival and a lower risk of disease progression. ${ }^{49}$ The findings of a multivariate analysis showed, among other factors, that the presence of a tumor clone without Sézary cells in the peripheral blood and folliculotropic mycosis fungoides are independent predictors of decreased survival and an increased risk of progression, while tumor distribution was found to be an independent predictor only for the risk of disease progression. ${ }^{49}$ In Sézary syndrome, atypical phenotypes and the characteristic loss of the surface markers CD7 and CD26 have also been identified as further negative prognostic factors. ${ }^{8}$

\section{TREATMENT}

\section{LOCAL THERAPEUTIC OPTIONS}

The topical drug substances used to treat mycosis fungoides and/or Sézary syndrome include class III-IV topical steroids and local cytostatic such as mechlorethamine. Topically applied bexarotene gel is also applied, a synthetic retinoid analog that presumably interacts with the genes responsible for cell control and thus inhibits tumor cell growth..$^{50,51}$

Patients with cutaneous lymphoma may also be treated with various forms of phototherapy. ${ }^{1}$ These therapies include narrow-band UVB treatment $(311 \mathrm{~nm})$ or PUVA treatment. ${ }^{1}$ In the latter form of photochemotherapy, UVA radiation is combined with the administration of psoralens that sensitize the skin to UV radiation and thus enhance the effects. ${ }^{52}$ Depending on the disease stage and severity, PUVA may be combined with systemic treatments such as oral bexarotene or alpha interferon. ${ }^{1} \mathrm{UV}$ light is also an important component of extracorporeal photopheresis (ECP). ECP starts with taking blood from the patient, from which the leukocytes are isolated by centrifugation (leukapheresis), treated with UV radiation and 8-methoxypsoralen and reinfused. ${ }^{53}$ The therapeutic effects of extracorporeal photopheresis are based on a modulation of the cellular immune system modulation which leads to a decrease in tumor activity. ${ }^{53}$ Another therapeutic option for patients suffering from mycosis fungoides is local radiotherapy, typically applied as electron or orthovoltage therapy in a total dose of 4 Gy to $40 \mathrm{~Gy}$ for localized, cutaneous B or T-cell lymphomas. ${ }^{1}$ However, low-dose HDR ${ }^{a}$ brachytherapy can also be used for effective and gentle treatment of sensitive skin areas, e.g., the face, in cases of mycosis fungoides. ${ }^{54} \mathrm{~A}$ special form of radiotherapy is total skin electron beam therapy (TSEBT) which is used in conventional (30-36 Gy) and low (10-12 Gy) doses can be applied in mycosis fungoides and Sézary syndrome. ${ }^{1}$

\section{SYSTEMIC TREATMENT OPTIONS}

Systemic treatment options for mycosis fungoides or Sézary syndrome include interferon-alpha, bexarotene, systemic steroids, and methotrexate. Alpha interferon, which is used to treat both mycosis fungoides and Sézary syndrome, is frequently used in combination with phototherapy, such as PUVA or extracorporeal photopheresis, but it may also be administered as monotherapy to maintain remission. ${ }^{1} \mathrm{~A}$ case study of a patient with mycosis fungoides showed that the use of alpha interferon after autologous stem cell transplantation maintained sustained complete remission of at least 17 months. ${ }^{55}$ The retinoid bexarotene, which is used as a topical agent in the earlier stages of the disease, may also be used as a systemic treatment, e.g. in combination with PUVA. ${ }^{1}$ Systemic steroids or other immunosuppressants such as methotrexate may also be considered in certain cases. ${ }^{3}$

Antibody-based therapies, e.g. rituximab, alemtuzumab, mogamulizumab, or brentuximab vedotin, offer further options for systemic treatment. ${ }^{56}$ In Switzerland rituximab, alemtuzumab, and mogamulizumab can be used as offlabel treatments for cutaneous lymphomas. In the EU, mogamulizumab is authorized for the treatment of adult patients with mycosis fungoides or Sézary syndrome, provided that the patients have undergone at least one prior systemic treatment. ${ }^{57}$ Mogamulizumab, a monoclonal antibody to the type $4 \mathrm{C}-\mathrm{C}$ chemokine receptor (CCR4) expressed on tumor cells in cutaneous lymphomas, ${ }^{26}$ exerts its effects via antibodydependent, cell-mediated cytotoxicity, i.e. destruction of antibody-bound tumor cells by effector cells of the patient's own immune system. ${ }^{26}$ Brentuximab vedotin has approval in the EU and Switzerland for treating patients with CD30positive cutaneous $\mathrm{T}$-cell lymphoma, provided that the patients exhibited disease progression during systemic treatment or if no other systemic treatment represents a feasible alternative. ${ }^{58,59}$ Brentuximab vedotin contains a monoclonal, CD30-specific antibody coupled via an amino acid linker to the proapoptotic anti-microtubule agent monomethyl auristatin E (MMAE).$^{60}$ CD30 itself is a transmembrane cytokine receptor that may be expressed on the surface of tumor cells in different types of non-Hodgkin's lymphomas, among others. ${ }^{60}$ In an open-label phase III trial, 131 pre-treated patients with CD30-positive mycosis fungoides or CD30-positive primarily cutaneous, anaplastic, large-cell lymphoma (pcALCL) were either treated with brentuximab vedotin or a treatment selected by their physician. ${ }^{61}$ The results showed that a response to treatment with brentuximab vedotin was observed in $56.3 \%$ of the patients over a period of at least 4 months, compared to $12.5 \%$ in the control group, which is a highly significant difference of 43.8 percentage points (95\% CI: $29.1-58.4 ; \mathrm{p}<0.0001) .{ }^{61}$ 
In patients with advanced-stage mycosis fungoides or Sézary syndrome, systemic chemotherapies depending on the entity may also be considered. These include mono-chemotherapies with chlorambucil, methotrexate, gemcitabine, liposomal doxorubicin or pralatrexate, or combined chemotherapy regimens, such as $\mathrm{EPOCH}^{\mathrm{b}}$ or $\mathrm{CHOP} .{ }^{1,3,56}$ Allogeneic stem cell transplantation is the only potentially curative option in patients with advanced-stage mycosis fungoides or Sézary syndrome. ${ }^{5}$

\section{GUIDELINE-COMPLIANT MANAGEMENT}

Treatment of mycosis fungoides and Sézary syndrome depends on the stage of the disease, the prognosis, and pre-treatments. ${ }^{1}$ In general, local, milder forms of treatment are preferentially applied in the early stages with a less aggressive course of mycosis fungoides, while, as the disease progresses systemic, more aggressive forms of treatment are increasingly used and may be combined with local treatment in some cases. ${ }^{1}$ Mycosis fungoides and Sézary syndrome in Switzerland is mainly treated in accordance with the EORTC guidelines. ${ }^{48}$

\section{MYCOSIS FUNGOIDES}

In the early stages of mycosis fungoides (IA to IIA) the first/ line therapy includes topical steroids, UV treatments (UVB, PUVA), local radiotherapy, or topical mechlorethamine. ${ }^{48}$ As second-line treatments retinoids, such as bexarotene or alpha interferon, low-dose methotrexate, or total skin electron beam therapy are recommended. ${ }^{48}$ In stage IIB, in addition to retinoids, alpha interferon, total skin electron beam therapy and low-dose methotrexate, which have already been mentioned, potential first-line treatments include monochemotherapy, e.g. with gemcitabine or pegylated liposomal doxorubicin, and localized radiotherapy (add-on therapy). ${ }^{48}$ In the second line, polychemotherapies (e.g., CHOP) and - in selected patients allogeneic stem cell transplantation are conceivable options. ${ }^{48}$ For more advanced disease (IIIA to IVB), extracorporeal photopheresis (IIIA and B), the anti-CD52 antibody alemtuzumab (IVB) and allogeneic stem cell transplantation are further treatment options in addition to the listed therapy options for stage IIB. (Table 4). ${ }^{48}$

\section{SÉZARY SYNDROME}

Recommended first-line treatments for Sézary syndrome, which typically follow an aggressive clinical course, are extracorporeal photopheresis (ECP), a combination of chlorambucil and prednisone, systemic treatment with retinoids or alpha interferon combined with PUVA or ECP and low-dose methotrexate. ${ }^{48}$ Potential second-line treatment options include chemotherapy, which is either administered as monotherapy, or as part of a chemotherapy regimen, alemtuzumab and allogeneic stem cell transplantation in selected patients. ${ }^{48}$

Table 4. EORTC guideline recommendations for treating mycosis fungoides. $\mathrm{CHOP}$, Chemotherapy with cyclophosphamide, hydroxydaunomycin, vincristine, prednisolone; ECP, Extracorporeal photopheresis; IFNa, Alpha interferon; MTX, Methotrexate; PUVA, Psoralen plus UVA radiation; TSEB, Total skin electron beam therapy; UVB, UVB radiation (according to ${ }^{48,62}$ ).

\begin{tabular}{|c|c|c|}
\hline MF stage & First-line treatment & Second-line treatment \\
\hline IA-IIA & $\begin{array}{l}\text { - Expectant policy (watch and wait) (mainly IA) } \\
\text { - Topical corticosteroids (mainly T1a and T2a) } \\
\text { - Topical mechlorethamine (IA/IB) } \\
\text { - UVB } \\
\text { - PUVA } \\
\text { - Local radiotherapy (unilesional MF/pagetoid reticulosis) }\end{array}$ & $\begin{array}{l}\text { - Retinoids/IFN-a } \\
\text { - TSEB (mainly T2b) } \\
\text { - MTX, low-dose }\end{array}$ \\
\hline IIB & $\begin{array}{l}\text { - Retinoids/IFN-a } \\
\text { - TSEB } \\
\text { - Monochemotherapy (gemcitabine, pegylated liposomal } \\
\text { doxorubicin) } \\
\text { - MTX, low-dose } \\
\text { - Local radiotherapy }\end{array}$ & $\begin{array}{l}\text { - Polychemotherapy (CHOP/CHOP-like chemotherapy) } \\
\text { - Allogeneic stem cell transplantation }\end{array}$ \\
\hline IIIA and IIIB & $\begin{array}{l}\text { - Retinoids/IFN- } a \\
\text { - ECP, in combination as indicated } \\
\text { - MTX, low-dose } \\
\text { - TSEB }\end{array}$ & $\begin{array}{l}\text { - Monochemotherapy (gemcitabine, pegylated liposomal } \\
\text { doxorubicin) } \\
\text { - Allogeneic stem cell transplantation }\end{array}$ \\
\hline IVA and IVB & $\begin{array}{l}\text { - Chemotherapy (gemcitabine, pegylated liposomal } \\
\text { doxorubicin, CHOP, CHOP-like chemotherapy) } \\
\text { - Radiotherapy (local, TSEB) } \\
\text { - Alemtuzumab (mainly B2) } \\
\text { - Allogeneic stem cell transplantation }\end{array}$ & \\
\hline
\end{tabular}




\section{THERAPIES UNDER DEVELOPMENT}

The therapeutic landscape for cutaneous lymphomas, such as mycosis fungoides and Sézary syndrome, is changing, with several substances currently in various stages of clinical trials. These include, for example, topical resiquimod, which binds to the Toll-like receptors TLR7 and TLR8, inducing an inflammatory response and activating the immune system. ${ }^{60}$ This immunomodulator has shown promising clinical efficacy and good tolerability in the treatment of cutaneous T-cell lymphomas. ${ }^{60}$ Several systemic, antibody-based drugs are also currently being tested in clinical trials, e.g., cobomarsen (anti-miR-155 antibody), TTI-621 (anti-CD47 antibody), IPH4102 (anti-KIR3DL2 antibody), atezolizumab (antiPD-L1 antibody), and alemtuzumab (anti-CD52 antibody), which bind to their target structures and ultimately induce tumor cell death through various pathways. ${ }^{60}$ In addition to these antibodies, substances with other modes of action are currently being investigated. Duvelisib, an inhibitor of both PI3K-isokinases ${ }^{\mathrm{c}} \mathrm{PI} 3 \mathrm{~K}-\delta$ and PI3K- $\gamma$, and E7777, a recombinant cytotoxic interleukin-2 fusion protein that inhibits cellular protein synthesis, as well as talimogene laherparepvec ( $t-v e c)$, an attenuated type 1 herpes simplex

\section{CONCLUSIONS}

Patients with mycosis fungoides or Sézary syndrome depending on the entity and stage of the disease - differ considerably in terms of clinical manifestations, prognosis and required treatment. ${ }^{1}$ Both of these conditions are rare, therefore, patients should preferably be closely monitored in a specialized center by an interdisciplinary team of dermatologists, pathologists, radio-oncologists, oncologists and hematologists. ${ }^{1,3}$ Such specialized centers can offer diagnostic possibilities in cases that are difficult to classify and can carry out specific, complex therapeutic measures as well as facilitate the patients' access to respective clinical studies. ${ }^{56}$ Here, cooperation with the general practitioner is suggested, for instance, the regular laboratory tests required during therapy may also be carried out at a primary care practice. ${ }^{63}$ Both the specialists from the disciplines involved and the primary care providers thus perform important tasks in the care of patients. virus that induces an immune response directed against the tumor cell, leading to oncolysis. ${ }^{60}$ Some of the treatments that are currently under investigation show high response rates, but may also be associated with considerable toxicity. ${ }^{60}$ Further larger-scale studies are needed to evaluate these forms of treatment. ${ }^{60}$

\section{FOLLOW-UP}

Patients with mycosis fungoides or Sézary syndrome who have stable disease or only exhibit a partial response to treatment, require ongoing treatment. Therefore, the recommendations for follow-up primarily apply to patients in complete remission. ${ }^{1}$ The primary objective of follow-up in these patients is recognition of recurrence, metastases, and secondary lymphomas, as well as any adverse reactions associated with the treatment, e.g., PUVA-related tumors as early as possible so that appropriate measures can be taken if necessary. ${ }^{1}$ The frequency and form of examinations depend on the stage of the disease. ${ }^{1}$

\section{TAKE HOME MESSAGES}

- Mycosis fungoides and Sézary syndrome, two subgroups of cutaneous T-cell lymphomas, are rare diseases whose etiology is still not fully understood.

- Mycosis fungoides and Sézary syndrome are considered as separate entities because of the differences in terms of pathogenesis, clinical manifestations and prognosis. Diagnosis, staging and also the subsequent therapy planning for mycosis fungoides and Sézary syndrome are based on a detailed medical history precisely documented skin examination, histological examinations (including immunophenotyping and clonality detection if required), laboratory analyses (including flow cytometry or respectively FACS). Treatment of mycosis fungoides and Sézary syndrome depends on the disease stage, prognosis, and pretreatments. Generally, local forms of treatment are preferred to treat the early, less aggressive stages of mycosis fungoides, while, as disease progresses to advanced stages, and in cases of Sézary syndrome, systemic and more aggressive forms of treatment are used, these may be combined with local treatment in some cases. 
REFERENCES

1. S2K Leitlinie der Cutaneous Lymphomas (ICD10 C82 - C86). AWMF 2016. [Accessed March 2021]. Available from: https://www.awmf.org/uploads/tx_szleitlinien/0320271_S2k_Kutane_Lymphome_2017-10-verlaengert_01. pdf

2. Swerdlow SH et al. The 2016 revision of the World Health Organization classification of lymphoid neoplasms. Blood. 2016; 127(20): 2375-90.

3. Willemze Ret al. Primary cutaneous lymphomas: ESMO Clinical Practice Guidelines for diagnosis, treatment and follow-up. Ann Oncol. 2018; 29 (Suppl-4): iv30-40.

4. Moritz R et al. Kutane Lymphome: Mycosis fungoides, Sézary-Syndrom, kutanes B-Zell-Lymphom. Haut. 2016; 3: $144-8$.

5. Jonak C. Die Klassifikation kutaner T-Zell-Lymphome. Spektrum Dermatol. 2019; 4: 12-6.

6. Mycosis fungoides (Übersicht). Altmeyers 2021. 6. Mycosis fungoides (Ubersicht). Altmeyers 2021. altmeyers.org/de/dermatologie/mycosis-fungoidesaltmeyers.org/

7. Orphanet. Sézary-Syndrom. [Accessed March 2021]. Available from: https://www.orpha.net/consor/cgi-bin/ OC_Exp.php?Expert=3162\&lng=DE

8. Dimitriou F et al. Lymphome: Das Sézary-Syndrom. Dermatolo Praxis. 2019; 29(6): 8-12.

9. Larocca C, Kupper T. Mycosis Fungoides and Sézary Syndrome: An Update. Hematol Oncol Clin North Am. 2019; 33(1): 103-20.

10. Willemze R et al. The 2018 update of the WHOEORTC classification for primary cutaneous lymphomas. Blood. 2019; 133(16): 1703-14.

11. Whittemore AS et al. Mycosis fungoides in relation to environmental exposures and immune response: a caseto environmental exposures and immune response: a case-

12. Netchiporouk E et al. Analysis of CTCL cell lines reveals important differences between mycosis fungoides/ Sézary syndrome vs. HTLV-1+ leukemic cell lines. Oncotarget. 2017; 8(56): 95981-98.

13. Jahan-Tigh RR et al. Hydrochlorothiazide and cutaneous $\mathrm{T}$ cell lymphoma: prospective analysis and case series. Cancer. 2013; 119(4): 825-31.

14. Jackow CM et al. HLA-DR5 and DQB1 03 class II alleles are associated with cutaneous T-cell lymphoma. J Invest Dermatol. 1996; 107(3): 373-6.

15. Park J et al. Genomic analysis of 220 CTCLs identifies a novel recurrent gain-of-function alteration in RLTPR (p.Q575E). Blood. 2017; 130(12): 1430-40.

16. Choi J et al. Genomic landscape of cutaneous $\mathrm{T}$ cell lymphoma. Nat Genet. 2015; $47(9)$ : 1011-9.

17. da Silva Almeida AC et al. The mutational landscape of cutaneous T cell lymphoma and Sézary syndrome. Nat 18.

18. Ungewickell A et al. Genomic analysis of mycosis fungoides and Sézary syndrome identifies recurrent alterations in TNFR2. Nat Genet. 2015; 47(9): 1056-60. 19. McGirt LY et al. Whole-genome sequencing reveals oncogenic mutations in mycosis fungoides. Blood. 2015; 126(4): 508-19.

20. Woollard WJ et al. Candidate driver genes involved in genome maintenance and DNA repair in Sézary syndrome. Blood. 2016; 127(26): 3387-97.

21. Guenova E et al. Classic Mediterranean Kaposi's sarcoma regression with sirolimus treatment. Arch Dermatol. 2008; 144(5): 692-3.

22. Blïmel $E$ et al. Staphylococcus aureus alpha-toxin inhibits CD8+ T cell-mediated killing of cancer cells in inhibits CD8+ T cell-mediated killing of cancer cells in
cutaneous T-cell lymphoma. Oncoimmunology. 2020; 9(1): 1751561 .

23. Ghazawi FM et al. Environmental and Other Extrinsic 23. Ghazawi FM et al. Environmental and Other Extrinsic Risk Factors Contributing to the Pathogenesis of Cutaneo 24. Campbell JJ et al. Sezary syndrome and mycosis fungoides arise from distinct T-cell subsets: a biologic rationale for their distinct clinical behaviors. Blood. 2010; 116(5): 767-71

25. Brunner PM. Neue Erkenntnisse zur Pathogenese von Mycosis fungoides und Sézary-Syndrom. Spektrum Dermatol. 2019; 4: 34-5.
26. Jonak $\mathrm{C}$, Knobler R. Überblick, Status quo und Ausblick: Primär kutane T-Zell-Lymphome. Spektrum Ausblick. Primär kutane

27. Scarisbrick JJ et al. The PROCLIPI international registry of early-stage mycosis fungoides identifies substantial diagnostic delay in most patients. $\mathrm{Br} J$ Dermatol. 2019; 181(2): 350-7.

28. Mangold AR et al. Early clinical manifestations of Sézary syndrome: A multicenter retrospective cohort study. J Am Acad Dermatol. 2017; 77(4): 719-27.

29. Krejsgaard $\mathrm{T}$ et al. Staphylococcal enterotoxins stimulate lymphoma-associated immune dysregulation. Blood. 2014; 124(5): 761-70.

30. Blümel E et al. Staphylococcal alpha-toxin tilts the balance between malignant and non-malignant CD4+ T cells in cutaneous T-cell lymphoma. Oncoimmunology. 2019; 8(11): e1641387.

31. Willerslev-Olsen A et al. Staphylococcus aureus 31. Willerslev-Olsen A et al. Staphylococcus aureus
enterotoxins induce FOXP3 in neoplastic T cells in Sézary enterotoxins induce FOXP3 in neoplastic T

syndrome. Blood Cancer J. 2020; 10(5): 57 .
32. Hodak E et al. Should we be imaging lymph nodes at initial diagnosis of early-stage mycosis fungoides? Results from the PROspective Cutaneous Lymphoma International Prognostic Index (PROCLIPI) international study. $\mathrm{Br}$ Dermatol. 2021; 184(3): 524-31.

33. Jawed SI et al. Primary cutaneous T-cell lymphoma (mycosis fungoides and Sézary syndrome): part I. Diagnosis: clinical and histopathologic features and new molecular and biologic markers. J Am Acad Dermatol. 2014; 70(2): 205.e1-16; quiz 221-2

34. Nickoloff BJ. Light-microscopic assessment of 100 patients with patch/plaque-stage mycosis fungoides. Am J

35. Edelson RL. Cutaneous T cell lymphoma: the helping hand of dendritic cells. Ann N Y Acad Sci. 2001; 941: 1-11. 36. Fink-Puches R, Cerroni L. Histopathologie, Immunhistologie und Molekularbiologie kutaner T-ZellLymphome. Spektrum Dermatol. 2019; 4: 22-5.

37. Robson A. The pathology of cutaneous T-cell lymphoma. Oncology (Williston Park). 2007; 21(2 Suppl 1): 9-12. 38. Cerroni L. Mycosis fungoides-clinical and
histopathologic features, differential diagnosis, and treatment. Semin Cutan Med Surg. 2018; 37(1): 2-10.

39. Vergier B et al. Transformation of mycosis fungoides: clinicopathological and prognostic features of 45 cases. French Study Group of Cutaneious Lymphomas. Blood. 2000; $95(7): 2212-8$.

40. Duvic M. CD30+ neoplasms of the skin. Curr Hematol Malig Rep. 2011; 6(4): 245-50.

41. Vonderheid EC et al. Update on erythrodermic cutaneous T-cell lymphoma: report of the International Society for Cutaneous Lymphomas. J Am Acad Dermatol. 2002; 46(1): 95-106

42. Willemze R et al. WHO-EORTC classification for cutaneous lymphomas. Blood. 2005; 105(10): 3768-85. 43. Scarisbrick JJ et al. Blood classification and blood response criteria in mycosis fungoides and Sézary syndrome using flow cytometry: recommendations from the EORTC cutaneous lymphoma task force. Eur J Cancer. 2018; 93: $47-56$.

44. Klemke CD et al. Histopathological and immunophenotypical criteria for the diagnosis of Sézary syndromephenotf in diferentiation from oth for erychrodermic skin diseases: Cancer (EORTC) Cutaneous Lymphoma Task Force Study Cancer (EORTC) Cutaneous Lymphoma Task Force
of 97 cases. Br J Dermatol. 2015; 173(1): 93-105.

45. Saulite I et al. Blockade of programmed cell death 45. Saulite I et al. Blockade of programmed cell death
protein 1 (PD-1) in Sézary syndrome reduces Th2 protein 1 (PD-1) in Sézary syndrome reduces Th2
phenotype of non-tumoral $T$ lymphocytes but may enhance tumor proliferation. Oncoimmunology. 2020; 9(1): 1738797

46. Kim YH et al. TNM classification system for primary cutaneous lymphomas other than mycosis fungoides and Sezary syndrome: a proposal of the International Society for Cutaneous Lymphomas (ISCL) and the Cutaneous Lymphoma Task Force of the European Organization of Research and Treatment of Cancer (EORTC). Blood. 2007; 110(2): 479-84.
47. van Dongen JJM et al. Design and standardization of PCR primers and protocols for detection of clonal immunoglobulin and T-cell receptor gene recombination in suspect lymphoproliferations: report of the BIOMED-2 Concerted Action BMH4-CT98-3936. Leukemia. 2003, 17(12): 2257-317.

48. Trautinger $\mathrm{F}$ et al. European Organisation for Research and Treatment of Cancer consensus recommendations for the treatment of mycosis fungoides/Sézary syndrome Update 2017. Eur J Cancer. 2017; 77: 57-74.

49. Agar NS et al. Survival outcomes and prognostic factors 49. Agar NS et al. Survival outcomes and prognostic factors in mycosis fungoides/Sezary syndrome: validation of the European Organisation for Research and Treatment of Cancer staging proposal. J Clin Oncol. 2010; 28(31):

50. Yang $G$ et al. Carfilzomib enhances natural killer cell-mediated lysis of myeloma linked with decreasing expression of HLA class I. Oncotarget. 2015; 6(29): 26982-94.

51. Bexarotene Gel (Targretin "Gel Formulation). Oncolink 2019. [Accessed September 2019]. Accessed from: https:// www.oncolink.org/cancer-treatment/oncolink-rx/ bexarotene-gel-targretin-r-gel-formulation.

52. S1 Leitlinie der Deutschen Dermatologischen Gesellschft zur UV-Phototherapie und Photoche cotochehttps://www.awmf.org/awmf-online-das-portal-derhttps://www.awmf.org/awmf-online-das-port
wissenschaftlichen-medizin/awmf-aktuell.html.

53. Worel $\mathrm{N}$ et al. Extrakorporale Photopherese. 53. Worel N et al. Extrakorporale
Transfusionsmedizin. 2016; 6(3): 115-22.

54. DeSimone JA et al. Low-dose high-dose-rate brachytherapy in the treatment of facial lesions of cutaneous T-cell lymphoma. J Am Acad Dermatol. 2013; 69(1): 61-5.

55. Doerschner $M$ et al. Interferon alfa-2a maintenance after salvage autologous stem cell transplantation in atypical mycosis fungoides with central nervous system involvement. Br J Dermatol. 2019; 181(6): 1296-302.

56. Gilson D et al. British Association of Dermatologists and U.K. Cutaneous Lymphoma Group guidelines for the management of primary cutaneous lymphomas 2018. Br J Dermatol. 2019; 180(3): 496-526.

57. Poteligeo" (mogamulizumab-kpkc). Summary of Product Characteristics. EMA. [Accessed March 2021]. Available from: https://www.ema.europa.eu/en/ documents/product-information/poteligeo-epar-productinformation_de.pd

58. Thestrup-Pedersen $\mathrm{K}$ et al. Lymphocytes from patient with cutaneous T-cell lymphoma show DNA instabilit and reduced DNA repair using the Comet assay. J Eur Acad Dermatol Venereol. 2017; 31(5): e224-5.

59. Adcetris $^{\circ}$ (brentuximab vedotin). Summary of Product Characteristics. EMA. [Accessed March 2021]. Available from: https://www.ema.europa.eu/en/documents/productinformation/adcetris-epar-product-information_de pdf

60. Ramelyte $\mathrm{E}$ et al. Investigative drugs for the treatment of cut Ramelyte Et al. Investigative drugs for the treatment of Opin Investig Drugs. 2019; 28(9): 799-809.

61. Prince HM et al. Brentuximab vedotin or physician's
61 Investig Drugs. $2019 ; 28(9): 799-809$. 61. Prince HM et al. Brentuximab vedotin or physician's
choice in CD30-positive cutaneous T-cell lymphom choice in CD30-positive cutaneous T-cell lymphoma
(ALCANZA): an international, open-label, randomised, phase 3, multicentre trial. Lancet. 2017; 390(10094): 555 -

62. Porkert S, Knobler R. Die EORTC-KonsensusBehandlungsempfehlungen für kutane T-Zell-Lymphome Spektrum Dermatol. 2019; 4: 26-8.

63. Conzett KB et al. Kutane Lymphome Stadieneinteilung und Therapieempfehlungen. Schweiz Med Forum. 2009; 9(42): 744-9. 